\title{
A SAÍDA DO MANICÔMIO: A CRISE DA CIDADE E O SURGIMENTO DO SER EM ENSAIO SOBRE A CEGUEIRA DE JOSÉ SARAMAGO.
}

\author{
Rodolfo Pereira Passos ${ }^{1}$
}

RESUMO: Em Ensaio sobre a Cegueira, romance de José Saramago, de 1995, o leitor se depara com uma desconcertante e imprevisível epidemia de "cegueira branca" instaurada em uma cidade anônima: ou seja, com relação à cidade representada, não há citações explícitas de tempo ou nomeações de espaço. Ainda assim, é inegável a percepção de algumas marcas contemporâneas que evidenciam um mundo semelhante e muito próximo ao que o leitor conhece, tais como automóveis, motoristas impacientes, sinais de trânsito, edifícios e construções luxuosas. Faz-se necessário compreender a cidade e todos os seus sentidos (antes e depois da epidemia), destacando o fato de que a nova luz feérica promoverá temor e pausa; um obstáculo à alienação urbana que, em outras palavras, pode significar uma crítica à noção de progresso. Procuraremos perceber como o romancista português utiliza-se destes dados, através de uma dominante ontológica e pós-moderna, para problematizar o ser humano e seu vínculo com um mundo marcado por um estado de "cegueira", e assim, através da ficção, compor seus questionamentos pautados na ética e na existência.

PALAVRAS-CHAVE: Cidade; Ficção Portuguesa; José Saramago; Pós-modernismo.

\section{LEAVING THE LUNATIC ASYLUM: \\ THE CRISIS OF THE CITY AND THE EMERGENCE OF BEING IN ENSAIO SOBRE A CEGUEIRA BY JOSÉ SARAMAGO}

\begin{abstract}
The novel Ensaio sobre a Cegueira (1995), by José Saramago, without explicit marks of time or space, the reader come across a baffling and unpredictable epidemic of "white blindness" in an anonymous city. However, there's no denying that some contemporary marks show a world similar to the reader's world: such as cars, impatient drivers, traffic lights, luxurious buildings and constructions. It's necessary to comprehend the city and all his senses (before and after the epidemic) and underline the new and extraordinary light will produce fear and break, that is, a barrier to urban alienation - in other words, a criticism of the notion of progress. We'll try to understand how the Portuguese writer has utilized these data through an ontological and postmodern dominant to analyze the human being and his connection with a world marked by a state of blindness, and then, through the fiction, to establish his questionings based on ethic and existence.
\end{abstract}

KEYWORDS: City; Portuguese Fiction; José Saramago; Post-modernism.

\footnotetext{
${ }^{1}$ Mestrando do Programa de Pós-Graduação em Estudos Literários da UNESP de Araraquara.
} 
No romance Ensaio sobre a Cegueira (1995), de José Saramago, duas cidades distintas são representadas, ou seja, duas cidades separadas por um manicômio-mundo. A primeira cidade compreende os cegos em sua cegueira de primeiro nível, uma visão comum de sentido alienado, no qual o homem pouco reflete sobre suas possibilidades de existência. Já a segunda cidade surge a partir da queda triunfal do manicômio, onde os cegos foram encerrados e no momento em que a cegueira branca é uma realidade indubitável.

Mônica Figueiredo (2006) salienta que a "cegueira" pode estar associada a uma incapacidade perceptiva que atinge o homem no espaço urbano. Faz-se necessário, então, compreender a cidade em todos os seus sentidos, pois, de acordo com Carlos Antônio Leite Brandão:

De fato, a cidade tem, como poucas realidades, o condão de exigir a mobilização tanto de variadas perspectivas disciplinares, quanto, mais decisivo, é o espaço-síntese, por excelência, da vivência social contemporânea em todas as suas virtualidades e desafios. Eleger a cidade, debruçar-se sobre ela, buscar compreendê-la, é um imperativo para os que entendem que o destino da cidade é, em grande medida, o destino do mundo contemporâneo (BRANDÃO, 2006, p.21).

Devemos compreender, por aí, que "as cidades são tanto os dados imediatos de suas materialidades, quanto o impalpável dos sonhos, dos desejos” (Ibidem, p.21). O homem começa a compreender que é o edificador da realidade, porém, por extensão, esta não passa de uma realidade construída, "forjada no encontro incessante entre os sujeitos humanos e o mundo onde vivem" (DUARTE JÚNIOR, 2004, p.12).

Em Ensaio sobre a Cegueira, há uma desorientação espacial, dentro do manicômio, com suas alas e corredores labirínticos e que, da mesma forma, ao sair dele, os cegos se deparam com uma cidade de "ruas estreitas" e "labirínticas" (SARAMAGO, 1995, p.274). Associamos que esta desorientação espacial pode estar na conjuntura de um sentido ontológico, como pode ser evidenciado pelo próprio Saramago, em uma de suas entrevistas:

Creio que dentro de nós há um espesso sistema de corredores e portas fechadas. Nós mesmos não abrimos todas as portas, porque desconfiamos que o que há do outro lado não será agradável de ver (...) vivemos numa espécie de alarme em relação a nós mesmos, que é que, talvez não queiramos saber quem somos na realidade. (apud AGUILERA, 2010, p. 143).

No romance em questão, a dicotomia entre saber e não saber quem é, na realidade, faz parte de um consequente desvelamento da verdade de cada personagem, uma vez que 
se constatou que "os cegos não precisam de nome", sendo cada um, somente a voz que tem e "o resto não é importante" (SARAMAGO, 1995, p.275). Os cegos se tornaram fantasmas vagando pelo "labirinto dementado da cidade" (Ibidem, p.211) e estão compreendendo que "ser fantasma deve ser isto, ter a certeza de que a vida existe, por que quatro sentidos o dizem" (Ibidem), contudo o fantasma não a pode ver, nem sabe qual caminho a vida em si tomará. Surge, assim, uma desterritorialização do espaço, no sentido em que "não há diferença entre o fora e o dentro, entre o cá e o lá" (SARAMAGO,1995,p.233) de um mundo inteiro labiríntico e similar, em simultaneidade com uma desterritorialização do ser, em que, agora, não há diferença "entre o que vivemos e o que teremos de viver" (Ibidem, p.233).

Com efeito, os elementos que unem os personagens saramaguianos são o desamparo e a perda de referências. Todas as referências já se encontram esvaziadas a partir do momento em que os personagens não possuem nome, o que pode também ser associado a uma problemática ontológica. É por este viés que a rapariga de óculos escuros admite que "dentro de nós há uma coisa que não tem nome, esta coisa é o que somos" (SARAMAGO, 1995, p.262). Acreditamos que tais palavras são importantes para um entendimento da questão do ser. Martin Heidegger ${ }^{2}$ esclarece que a todo o momento utiliza-se e compreende-se a palavra "ser", no entanto “essa compreensão comum demonstra apenas a incompreensão" (HEIDEGGER, 2002, p.29). O problema do ser na obra saramaguiana não possui filiação com noções transcendentes, ao mesmo tempo em que se encontra distante de um paradigma de consciência - como uma abordagem cartesiana que divide a realidade em sujeito e objeto. Heidegger, através do conceito de serno-mundo ${ }^{3}$, também refutava claramente esta separação.

\footnotetext{
${ }^{2}$ Gianni Vattimo (1996) deixa claro que existe a possibilidade de efetuar a conexão entre Heidegger e o pós-modernismo, uma vez que o prefixo "pós", agora, investe no desejo de por radicalmente em discussão um pensamento (ocidental). Porém, recusando-se a estabelecer uma ideia de novidade, para não se continuar preso nesta mesma lógica de desenvolvimento. Assim, para Vattimo, a modernidade pode ser caracterizada pela história do pensamento como uma "iluminação progressiva", que se desenvolve a partir de um fundamento pensado como origem. Desta forma, tradicionalmente, a modernidade tem o curso do pensamento como um desenvolvimento progressivo, identificando o "novo". Heidegger - assim como Nietzsche - podem ser considerados, segundo Vattimo, como filósofos da pós-modernidade, pois se distanciam criticamente do pensamento ocidental e sua ideia de fundamento, ao passo que não podem criticar este pensamento em nome de uma "fundação" mais verdadeira (VATTIMO, 1996).

${ }^{3}$ Heidegger, em Ser e Tempo, estabelece que o ser-no-mundo é, sem dúvida, uma constituição necessária e a priori da pre-sença, a estrutura ontológica do homem. Não compreende uma relação espacial de uma coisa "dentro de outra", mas significa "estar acostumado a" ou "habituado ao mundo". Vale salientar que a busca da verdade deve estar pautada na compreensão de que o homem não é mais o centro, o problema da existência humana não se reduz somente ao homem, mas ao problema do ser. Em Heidegger, a questão
} 
Concordamos com Mônica Figueiredo, quando salienta que "uma história de homens comuns é merecedora de recriação estética pelas linhas da ficção" (FIGUEIREDO, 2006, p.183), entretanto, estes homens fantasmas, deixados à margem pela sociedade, (como um velho, uma rapariga e um ladrão) se sentem igualados pelo anonimato da existência. São atuantes de um teatro de incertezas, que abarca todos os demais personagens e que "não raro eles irão protagonizar enredos que elegem a cidade como um espaço que, afetado de sentidos, não é mais um horizonte de ação, antes é um agente participante dela" (Ibidem). Assim, um estilhaço da identidade em paralelo com espaços labirínticos parece estar de acordo com uma busca do entendimento do ser e, por conseguinte, do homem pós-moderno. Neste viés, os cegos caminham errantes por uma cidade sem nome. São personagens que deflagram os estilhaços de um espaço pósmoderno, destituído de antigos e pretensos valores absolutos, reiterando, portanto, aquela ideia defendida por Jean Yves Tadié (1992) de que a morte do herói significou também a morte da cidade heroica.

Renato Cordeiro Gomes, por exemplo, ao analisar As cidades invisiveis de Ítalo Calvino, afirma que esta obra se inscreve numa linha de preocupação que marcou o final do século XX, ou seja, século por excelência da afirmação do urbano, mas que aponta também para um dado a ser considerado: o esgotamento da cena moderna e para a ultrapassagem dos valores utópicos da modernidade. Neste sentido, o ensaísta aponta um caminho de compreensão das cidades - retomando uma percepção de Marco Polo em $A s$ cidades Invisiveis, qual seja, o entendimento de que o inferno dos vivos não está por vir futuramente, mas, pelo contrário, está constantemente presente. Assim, a possível solução que nos cabe agora no âmbito do urbano é:

Ler as representações da cidade contemporânea na literatura contemporânea, percebendo a utopia em ruína e os traços infernais das megalópoles em que vivemos, sem, entretanto, abrir mão da capacidade de indignação e das possibilidades do presente, ainda que precário. A procura de uma operação poética para ler as cidades ficcionalizadas pela literatura pode, assim, ser revestida não só de preocupação política, mas sobretudo de postura ética (GOMES, 2000, p.30).

do ser e da verdade devem estar correlacionadas, contudo sabendo que o homem é um respondente privilegiado da existência, é aquele que pode levantar a questão do ser. De acordo com o filósofo alemão, "elaborar a questão do ser significa, portanto, tornar transparente um ente - o que questiona em seu ser (...). Esse ente que cada um de nós somos e que, entre outras, possui em seu ser a possibilidade de questionar, nós o designamos com o termo pre-sença." (HEIDEGGER, 2002, p.33). 
As realidades plurais começam a tornar-se evidentes na trama complexa do sujeito pós-moderno, pois a alienação na cidade sem nome encontra um sujeito questionador que faz parte desta complexidade em sentido positivo. Este sujeito tem a consciência que "a idade das cidades ideais caiu por terra” (GOMES, 2008, p.14).

Vale a pena frisar que "a questão da representação e/ou da referencialidade da obra de arte literária não parece, pois, ter deixado de ser problemática nos agitados e controversos tempos do presente" (ARNAUT, 2002, p.20). A crise da representação, porém, torna-se transparente na obra de Saramago, pois os personagens sem nome se encontram mergulhados em uma brancura luminosa total e lancinante, com exceção da mulher do médico ${ }^{4}$. A cidade sem nome também não escapa da mesma crise e de uma nova percepção para a arte, logo tais problemas se estabelecem como um desdobramento ontológico. O homem não é mais um escravo da realidade e é isso que Saramago procura propor a partir da efabulação de sua poética da luz branca.

É válido salientar, neste sentido, que Isabel Pires de Lima (2000), pautando-se também em Diane Elam (1992), ensina que a união do pós-modernismo com o romance desencadeou o excesso, e, assim, torna-se impossível o respeito a qualquer fronteira estética ou histórica. Percebe-se daí que Saramago não segue uma ideia de estética única, mas antes, promove um hibridismo de estilos, ou seja, ao mesmo tempo em que se verifica um aparente realismo, tem-se a rejeição dele. As convenções do realismo e do modernismo são apropriadas e subvertidas a todo momento. O código pós-moderno dá origem a uma relação entre o autor e o seu texto menos tensa: valoriza-se o arbitrário e o desconexo. Neste sentido, a escritura saramaguiana não segue qualquer tipo de convenção, o que forja a artificialidade da própria obra literária. Se verificarmos, por exemplo, que a proposta da obra (já no título) expõe uma linha de "ensaio" e não de "romance", isto significa também

\footnotetext{
${ }^{4}$ Há uma personagem na obra de Saramago capaz de dar conta de toda a dor e do drama vividos pelos cegos: a mulher do médico, precisamente a única que pode ver. Aí começa sua diferença e o nosso problema. Se possuir olhos comuns remete à alienação e a absorção de opiniões prontas, por que a mulher do médico também não pode ser considerada alienada? Devido, exatamente, pelo fato de que sua visão está permanentemente ligada a um senso de responsabilidade e preocupação pelo outro. O que se delineia agora é entender "se existe uma relação direta entre os olhos e os sentimentos ou se o sentido de responsabilidade é a consequência natural de uma boa visão" (SARAMAGO, 1995, p.243). A dúvida parece ser esclarecida com a singular figura desta mulher que, inserida no manicômio, por livre e espontânea vontade, passa pelo mesmo limite de sofrimento da condição humana dos demais cegos. Neste sentido, torna-se necessário investigar o sentido de responsabilidade do momento presente, ainda que representativo de um estado caótico, em que a razão não é mais guia para uma tomada de atitude: "É hoje que tenho responsabilidade, não amanhã, se estiver cega, Responsabilidade de quê [pergunta a rapariga de óculos escuros], A responsabilidade de ter olhos quando os outros os perderam" (SARAMAGO, 1995, p.241).
} 
tornar problemática a ideia de arte elevada ou ideal. O modernismo, com sua postura de vanguarda, tende a revelar as convenções usadas na construção de uma obra de $\operatorname{arte}^{5}$. Entretanto, isto é pouco para o pós-modernismo, que intenta mostrar que todo o resto também é uma invenção. Porém, já não veicula a sensação de novidade, originalidade e orgulho artísticos associados ao modernismo.

Parece ser, pois, na aposta de representação ontológica de um universo marcado pela "cegueira branca", que Saramago constrói a sua alegoria contemporânea finissecular novecentista, onde os próprios gêneros se correspondem, numa espécie de "teoria implícita que se ilustra pela narração" (CERDEIRA, 2000, p.254), em que a permuta salutar de categorias genológicas em trânsito no texto se realiza de maneira convincentemente estruturada.

Neste viés, o ensaio, enunciado no título, permite o leitor pensar, como bem sublinhou Maria Alzira Seixo, não num "romance-ensaio" ou num "ensaio de romance" (1999, p.108), mas num romance que reflete e ensaia sobre as situações geradas pela cegueira. Constitui-se, portanto, naquele exercício "performativo acutilante" (Ibidem, p.108) em que Saramago:

(...) Não narra uma alegoria onde implicitamente sugira o que está mal, e a forma como esse mal se torna em bem; diferentemente Saramago alerta para um perigo (o perigo de não se ver, de não se reparar) que, uma vez descrito ficcionalmente, não pode deixar de manter tudo na mesma, apenas acrescentado das marcas da deteriorização resultante (SEIXO, 1999, p.108).

Ensaiar sobre a cegueira dos homens contempla ainda a fatuidade do leitor comum, pois a cinese que envolve ficção e interpretação se faz a passos lentos. Porém, a arte e o homem se tornam altamente questionáveis. Ao colocar a dúvida perante suas "nobres intenções”, a ficção do en começou a tornar-se exacerbada e mais violenta. Daí,

\footnotetext{
${ }^{5}$ Vale a pena sublinhar que a autorreflexividade moderna estava ligada ao ideal de arte esteticamente elevada. Em sentido oposto se dá a metaficção pós-moderna, que não se limita apenas sobre suas próprias convenções de construção, como explica Maria Lucia Outeiro Fernandes: "Para compreender a metaficção pós-moderna é preciso considerar, entre outras coisas, como a própria noção de ficção se ampliou para outras áreas da sociedade e da cultura, com a penetração da estética de consumo e a consequente difusão de ilusões, entendidas como falsas promessas e necessidades forjadas, impostas para incrementar o consumo, no atual estágio do capitalismo. Portanto, é preciso considerar a propagação de realidades simuladas, imagens fictícias da sociedade, criadas e difundidas pelos meios de comunicação de massa”. (FERNANDES, 2011, p.229). Já Linda Hutcheon chama a atenção para o fato de que as convenções fictícias ou ilusionistas da arte são reveladas no pós-modernismo também com o objetivo de desafiar as instituições sociais. Assim, a autora esclarece que "antes de mais nada, as instituições passaram a ser submetidas a investigação: desde os meios de comunicação até as universidades, desde os museus até os teatros" (HUTCHEON, 1991, p.26).
} 
encontramos no romance de Saramago um desejo veemente pelo invisível, sonhado e rejeitado. Como um niilismo que já não se quer algoz, mas pretende, sorrateiramente, mirificar toda sabedoria inabalável, em forma de catástrofe luminosa, tão total que devorará mais do que absorve, "não só as cores, mas as próprias coisas e seres, tornando-as por essa maneira duplamente invisíveis" (SARAMAGO, 1995, p.16). A cegueira branca se diferencia, assim, da cegueira comum, uma vez que esta última, como simples ausência da luz, ainda deixaria a realidade intacta. A cegueira branca, entretanto, tem o poder de dissipar todas as convicções estabelecidas. A dúvida instaurada, princípio do desespero, mostra-se inteiramente produtiva, posto que a irremissível atividade de questionar não deixa mais nada intacto. Constitui-se, portanto, um mergulho temido e desejado.

Neste viés, Linda Hutcheon (1991) lembra que, na condição pós-moderna, o ideológico e o estético tornaram-se inseparáveis. Assim, a arte não escapa do ideológico e o pensamento pós-moderno compreende essa conexão inescapável, porém sabe que não está produzindo ideias mais verdadeiras que as anteriores. A diferença essencial é o questionamento incessante. Trata-se de um marco inovador, porém não mais sublime. Em outras palavras, o romance pós-moderno não é apenas uma descentralização verbal do mundo ideológico, uma vez que ele começa criando e centralizando um mundo, para depois contestá-lo. O romance não quer, por meio da ficção, persuadir seus leitores quanto à correção de uma forma específica de interpretar o mundo. Em vez disso, nos termos de Linda Hutcheon (1991), o romance fará com que os leitores questionem todas as suas interpretações.

É compreensível que, na transição do moderno para o pós-moderno, os homens comecem a tomar consciência dos paradoxos que compõem suas vidas. A cidade como ambiente construído, lembra Renato Cordeiro Gomes, também faz parte de tal elenco, posto que se constitui um "contingente das experiências humanas, com os quais está em permanente tensão" (GOMES, 2008, p.23). Logo, ela torna-se uma espécie de livro de registros, de materialização dessas experiências e de sua própria história. Entretanto, este livro da cidade transforma-se em um labirinto de textos, ou seja, textos que conduzem a outros textos, como ainda explica o ensaísta brasileiro:

O texto é o relato sensível das formas de ver a cidade; não enquanto mera descrição física, mas como cidade simbólica, que cruza lugar e metáfora, produzindo uma cartografia dinâmica, tensão entre racionalidade geométrica e emaranhado de existências humanas. Essa cidade torna-se um labirinto de ruas feitas de textos, essa rede de 
significados móveis, que dificulta a sua legibilidade. (GOMES, 2008, p.24)

A partir de então, o encontro da cidade constitui-se também o desencontro do ser. Entretanto, em relação ao romance de Saramago, trata-se de um desencontro precioso, pois as possibilidades de compreensão da vida são imanentes à própria condição da cidade labiríntica. Corre nas veias do desamparo um encantador adágio de liberdade e, desta forma, a saída do manicômio se faz como caminhada e presença existencial concordes. Assim, o mundo contemporâneo vem ao encontro dessa tensão como possibilidade de alívio para o enfastiamento da alma. Contudo, não é tão pleno o homem que, neste mundo, enxerga o desamparo como quem se mira ao espelho.

Se analisarmos, ainda, a primeira cidade, anterior à instauração da epidemia de cegueira branca, verificaremos a inervação do isolamento e da impaciência. Em Ensaio sobre a Cegueira, esta questão torna-se evidente logo na abertura do romance, pela apresentação do espaço urbano. "Os automobilistas, impacientes, com o pé no pedal da embraiagem, mantinham em tensão os carros, avançando, recuando, como cavalos nervosos que sentissem vir no ar a chibata" (SARAMAGO, 1995, p.11). Esta é a imagem inicial dada pelo narrador da trama, e nela é possível perceber sujeitos inseridos na metrópole, marcados por um desejo de continuar seguindo os mesmos caminhos, não pensando na direção de suas vidas, posto que a sinergia da cidade não permite nenhuma pausa. Esta situação promove o nervosismo constante e o narcisismo dos habitantes da cidade, acostumados a não perceberem o outro, como bem sublinhou Mônica Figueiredo: "Dentro do espaço urbano os apelos sempre são muitos e a solidariedade deve ser mantida num nível de confortável superficialidade, evitando-se o envolvimento emocional" (FIGUEIREDO, 2011, p.242).

Tudo tenderia, portanto, ao movimento, mas desde que pautado por gestos superficiais e pela alienação. Nenhum ser poderia ou deveria interromper o fluxo da cidade. Neste sentido, a instauração da cegueira branca se colocaria contra a ordem instituída. Enquanto recurso efabular na trama romanesca, ela constitui-se numa pausa rejeitada, mas necessária, obstáculo à alienação urbana e à precariedade do banal. A luz feérica, que promove temor e pausa, estabelece também uma nova condição para os homens, pois, segundo Mônica Figueiredo,

A partir de então, aquele que até ali era chamado de "homem", é agora nomeado por "cego", selando no nome uma nova condição de existência. A desordem instituída pela epidemia de cegueira substituirá de forma cruel a ordem cegante anterior (a que, entretanto, já estavam 
acostumados os habitantes dessa metrópole finissecular), fazendo com que não possa deixar de ser vista por olhos habitualmente alheados do questionamento. (...) a cegueira tornar-se-á necessária para que as indagações sejam reconduzidas ao discurso que o tempo normalizou como assertivo, de modo que os novos cegos terão de perguntar "o que nos aconteceu?" (FIGUEIREDO 2011, p.242).

No romance em questão, esta pausa significa, em outras palavras, uma crítica à noção de progresso, conforme se pode constatar nas considerações do narrador: "A consequência foi perderem as últimas ilusões aqueles que ainda as tinham, daí em diante não se ouviu mais um ruído de motor, nenhuma roda, grande ou pequena, rápida ou lenta, voltou a pôr-se em movimento" (SARAMAGO, 1995, p. 127).

Assim apresenta-se composta a poética da cegueira-branca. Uma reflexão e uma consolidação do "ser-no-mundo" se desdobram agora em uma atividade de questionamento de todos os valores, antigamente perenes e continuamente frágeis. Os personagens saramaguianos, após a saída do manicômio, se deparam com uma cidade completamente devastada, mas nem por isso poderão escapar a este novo sentido de caos que lhes foi apresentado, posto que o espaço da "urbes" abre uma nova possibilidade do homem travar contato com o mundo. Tal conexão pressentida na trama ficcional de Saramago permite, assim, um jogo de leituras entre sujeitos em trânsito e espaços devastados. ${ }^{6}$ Ora, se "ler a escrita da cidade e a cidade como escrita é buscar o legível num jogo aberto e sem solução" (GOMES, 2008, p.18), a pós-modernidade, neste sentido, não pode ser entendida a partir de um reconhecimento de vínculo com a modernidade na qual as armadilhas continuam eternamente expostas ao sujeito que, apenas, começou a perceber sua impossibilidade de desarmá-las? Com a "espessura do nevoeiro branco" (SARAMAGO, 1995, p.128), torna-se utópica a ambição de controlar o caos. Perde-se a incumbência de se impor limites a qualquer estado caótico da cidade. Este intento foi

\footnotetext{
${ }^{6}$ Interessante a visão de Carlos Antônio Leite Brandão, quando considera a convocação da literatura e das artes como acesso privilegiado à compreensão das cidades. Assim "a cidade como promessa de libertação e felicidade tem lugar importante na obra de Tchecov, por exemplo. Suas personagens femininas, quase sempre oprimidas pelo ambiente opaco do campo, sonham com a cidade grande como libertação. É também decisivo o papel das cidades grandes, Paris, São Petersburgo, Berlim, Londres como veículos de corrupção e perdição sobre certas vontades frouxas, como se vê nas obras de Balzac, de Dickens, de Dostoievski, de Alfred Doeblin". (BRANDÃO, 2006, p.22). Entretanto, a libertação em Saramago se assemelha mais às palavras de Jean-Yves Tadié ao abordar a Viena de Robert Musil, em $O$ Homem sem qualidades, ou seja, trata-se de "uma situação paradoxal: a cidade domina a narração, e contudo não é admirável, já não tem sentido. (...) A Viena de Musil não é um sonho nem sequer um mito, mas uma ideia caduca, um conceito fora de moda, inutilizável" (TADIÉ, 1992, p.146).
} 
proposto, uma vez, pela Bauhaus, no desejo da forma controlar a própria realidade. Logo, tratava-se de uma aspiração tipicamente moderna:

A metrópole capitalista com a vida angustiante, os intermináveis atentados aos seus habitantes, converte-se em constante estímulo para a modernidade e as vanguardas que encontram aí o lugar ideal para produzir e confrontar suas propostas. A grande cidade se converte em depositária de todas as paixões. As diversas linguagens e aspirações artísticas e ideológicas medem-se por sua relação com o metropolitano. A cidade aparece como o lugar por excelência onde se sentem, de forma mais agudizada, as consequências do desenvolvimento do sistema capitalista e da Revolução Industrial.

Neste contexto, inserem-se as propostas utópicas da Bauhaus, no desejo de controlar formalmente a realidade. Frente ao mal-estar gerado pelas novas morfologias espaciais da estrutura social, frente ao caos da cidade, caberia convertê-lo em forma, caberia resistir à evanescência do lugar. (GOMES, 2008, p.36)

Matei Calinescu, por sua vez, deixa bastante claro que "o mais óbvio modelo pósmodernista inclui um novo uso do perspectivismo narrativo existencial ou 'ontológico', diferente do perspectivismo, sobretudo, psicológico, que se encontrava no modernismo" (CALINESCU, 1999, p. 262). Calinescu, assim, consegue evidenciar, retomando alguns princípios norteadores de Brian McHale, que os questionamentos modernistas levados ao extremo irão produzir sem escapatória um questionamento ontológico pós-moderno. Sabese que para McHale (1987), a dominante da escrita pós-moderna é ontológica, ou seja, no sentido que quer levantar questões sobre a existência de mundos possíveis. É importante deixar claro, portanto, que a dominante da escrita modernista é epistemológica. Ou seja, o que existe para ser conhecido torna-se ainda uma questão central. O conhecimento sobre o mundo não havia sido pensado como pura invenção. A utopia do "pensamento forte" era ainda parte constitutiva de sua visão, com certa mostra de radicalismos. Em outras palavras, a inocência do ato de conhecimento (dominante epistemológica) não havia se reconhecido como inocência. Não percebeu, assim, sua cegueira inerente. A progressão do conhecer na pós-modernidade não poderá vencer sua infinita lassidão dentro do labirinto, pois, ainda de acordo com os pressupostos de McHale, a lógica do questionamento nunca é linear, com direção única, mas circular e reversível (CALINESCU, 1999). Por isso, é plausível, desde sempre, a sondagem ontológica e pós-moderna da verdade.

Agora, o questionamento incessante deve ser tomado como primordial, ainda que a busca seja alimentada também por desejos utópicos, a utopia, agora reinventada, deverá ser “a explicitação da luta contra a dominação e a injustiça” (BRANDÃO, 2006, p. 28). A proposta de Saramago, de maneira essencial, diz respeito a certos pressupostos caros a uma 
poética pós-moderna, no sentido de que, no seu romance Ensaio sobre a cegueira, se percebe aquela mesma "tentativa de verificar o que ocorre quando a cultura é desafiada a partir de seu próprio interior: desafiada, questionada ou contestada, mas não implodida" (HUTCHEON, 1991, p.16), nos termos expostos por Linda Hutcheon. Não podemos esquecer que "a dimensão crítica do pós-modernismo reside precisamente em seu radical questionamento daquelas pressuposições que ligaram o modernismo e a vanguarda aos propósitos da modernização" (HUYSSEN, 1991, p.24). Ou seja, o que se tem em mente é o questionamento da própria modernidade e de todas as formas de representação. A atividade de questionar se adequou, na obra de Saramago, à própria fragilidade do homem e da realidade.

\section{Bibliografia}

AGUILERA, Fernando Gomez (sel. e org.). As palavras de Saramago. São Paulo: Companhia das Letras, 2010.

ARNAUT, Ana Paula. Post-modernismo no romance português contemporâneo. Coimbra: Almedina, 2002.

BRANDÃO, C. A. Leite. As cidades da cidade. Belo Horizonte: Editora UFMG, 2006.

CALINESCU, Matei. As cinco faces da modernidade: Modernismo, Vanguarda, Decadência, Kitsch, Pós-modernismo. Tradução Jorge Teles de Menezes. Lisboa: Vega, 1999.

CERDEIRA, Teresa Cristina. O avesso do Bordado. Lisboa: Caminho, 2000.

DUARTE JÚNIOR, J.O que é realidade. 10ª Ed. São Paulo: Brasiliense, 2004.

ELAM, Diane. Romancing the Postmodern. London: Routledge, 1992.

FERNANDES, Maria Lúcia Outeiro. Narciso no labirinto de espelhos: perspectivas pósmodernas na ficção de Roberto Drummond. São Paulo: Cultura Acadêmica, 2011.

FIGUEIREDO, Mônica. No corpo, na casa e na cidade: as moradas da ficção. Rio de Janeiro: Língua Geral, 2011.

"Da cegueira à lucidez: o ensaio de um percurso. Algumas notas sobre a narrativa de José Saramago" In: Diadorim: Revista de Estudos Lingüísticos e 
Literários, n.1. Rio de Janeiro: UFRJ, Programa de Pós-Graduação em Letras Vernáculas, p. 181-190, 2006.

GOMES, Renato Cordeiro. Todas as cidades, a cidade: literatura e experiência urbana. Rio de Janeiro: Rocco, 2008.

"A cidade moderna e suas derivas pós-modernas". In: Revista Semear, Rio de Janeiro, nº 4, p.29-37, 2000.

HEIDEGGER, Martin. Ser e Tempo. Parte I. 12a ed. Trad.: Márcia Sá Cavalcante Schuback. Petrópolis: Editora Vozes, 2002

HUTCHEON, Linda. Poética do Pós-Modernismo. Trad.: Ricardo Cruz. Rio de Janeiro: Imago, 1991.

HUYSSEN, Andreas. "Mapeando o pós-moderno”. In: HOLLANDA, Heloísa (org.). Pósmodernismo e política. Rio de Janeiro: Rocco, p. 15- 80, 1991.

LIMA, Isabel Pires de. “Traços pós-modernos na ficção portuguesa atual” In: Revista Semear. Rio de Janeiro, nº4, p. 9-28, 2000.

McHALE, Brian. Postmodernist Fiction. London and New York: Routledge, 1987.

SARAMAGO, José. Ensaio sobre a Cegueira. São Paulo: Companhia das Letras, 1995.

SEIXO, Maria Alzira. Lugares da ficção em José Saramago. Lisboa: Imprensa Nacional - Casa da Moeda, 1999.

TADIÉ, Jean-Yves. O romance no século XX. Trad.: Miguel Serras Pereira. Lisboa: Dom Quixote, 1992.

VATTIMO, Gianni. O fim da modernidade: Niilismo e Hermenêutica na cultura pósmoderna. Trad.: Eduardo Brandão. São Paulo: Martins Fontes, 1996.

Artigo recebido em: 31 de Agosto de 2012.

Artigo aprovado em: 15 de Outubro de 2012. 